\title{
GASPAR NICOLAS E OS 500 ANOS DO TRATADO DA PRATICA D'ARISMETICA (15 DE NOVEMBRO DE 1519)
}

\author{
Teresa Costa Clain \\ Universidade de Aveiro-CIDMA- Portugal
}

(aceito para publicação em novembro de 2019)

\begin{abstract}
Resumo
Comemora-se em 2019 (15 de Novembro) os quinhentos anos do Tratado da Pratica d'Arismetica de Gaspar Nicolas. Esta obra foi o primeiro tratado de aritmética prática de autor português publicado em Portugal. Pertence a um conjunto de livros que entraram em cena numa época marcada por uma vontade de perpetuar na forma escrita o conhecimento outrora transmitido oralmente. Para esta mudança contribuíram a emancipação das línguas vernáculas relativamente ao latim e a eclosão da imprensa.

O tratado insere-se ainda numa época de grande desenvolvimento comercial, com necessidades de modelos, para programar os grandes negócios associados à expansão marítima e comercial, utilizando algoritmos apoiados na vulgarização do cálculo com os números indo-árabes. À semelhança de outras obras para o mesmo fim, o tratado de Gaspar Nicolas refere alguns pontos de negócio e trata problemas ligados ao «Novo Mundo». São exemplo disso os enunciados sobre o negócio de especiarias com as respetivas quebras na mercadoria devido às más condições das viagens, uma realidade sentida por navegantes e mercadores.

O Tratado da Pratica d'Arismetica aborda ainda temas «clássicos», tais como, como as progressões, raízes quadradas e cúbicas, os problemas para determinar números, entre outros que, embora desligados do mundo mercantil, assumiram um lugar de destaque no saber matemático da época. Estes temas estão associados a processos calculatórios, contudo, apresentam esboços de um ideal muito próximo do pensamento matemático.

O conhecimento dos algoritmos das operações básicas e a consolidação da sua prática através de problemas é uma vertente de importância didático-pedagógica crucial e está presente no tratado e nas preocupações de bem ensinar do seu autor. Na obra destacamse três princípios: realizar a transcrição do conhecimento oral para o escrito, explorar as vantagens da matemática calculatória, algorítmica e comercial, introduzir temas matemáticos que aparentemente nada têm a ver com os aspetos comerciais.
\end{abstract}


Palavras-chave: Matemática, História, Século XVI, aritmética, Portugal, Gaspar Nicolas, Tratado da Pratica d'Arismetica, problemas, regras comerciais.

\title{
[GASPAR NICOLAS AND THE 500 YEARS OF THE TRATADO DA PRATICA D'ARISMETICA (NOVEMBER 15, 1519)]
}

\begin{abstract}
In 2019 (November 15), the five hundred years of the Tratado da Pratica d'Arismetica of Gaspar Nicolas is celebrated. This document was the first treaty of practical arithmetic published in Portugal. It encompasses in a series of books that emerged at a time marked by the emancipation of vernacular languages from Latin, the beginning of the press, and point out the ambition to perpetuate in a book the knowledge formely transmitted orally.

The treaty is connected to great commercial development, where arithmetical models turn to be necessary for organizing the large businesses campaign associated with maritime and commercial expansion, by using algorithms supported by the vulgarization of the calculation with Indo-Arab numbers. Like similar works with the same goal, Gaspar Nicolas's treatise is dedicated to business problems and addresses issues related to the 'New World'. Noticeable examples are the statements about the spice business and their breakdowns in merchandise due to poor travel conditions.

The Tratado da Pratica d'Arismetica also addresses 'classic' themes such as progressions, square and cubic roots, problems with numbers, and others which, although disconnected from the mercantile world, have taken a prominent place in the mathematical knowledge of the epoch. Such themes are associated with calculation procedures, however, they present sketches of an ideal very close to the mathematical thinking.

The algorithms' knowledge of basic operations and the consolidation of their practice through various problems, is a crucial contribution from the didactic and pedagogical point of view Such a concern is present all along the treatise and highlights the author commitment in well teaching. The book principle is threefolds: to carry out the transcription of oral knowledge into written document, to explores the advantages of calculation, algorithms and commercial mathematics, to introduce more mathematical themes that apparently have nothing to do with commercial aspects.
\end{abstract}

Keywords: Mathematics, History, 16th century, arithmetic, Portugal, Gaspar Nicolas, Treaty of Pratica d'Arismetica, problems, trade rules. 


\section{Introdução}

Gaspar Nicolas, aritmético português, ao esclarecer as dúvidas em aritmética a D. Rodrigo, Conde de Tentúgal, sentiu-se motivado a escrever sobre aritmética. Este propósito, aparentemente isolado, deu origem ao primeiro tratado português de aritmética prática, o Tratado da Pratica d'Arismetica, publicado em 15 de Novembro de 1519.

Podemos afirmar que aquela obra «nasceu em berço de ouro». A época de Quinhentos foi marcada por grandes mudanças no meio socioeconómico do reino, projetadas também na Europa como o refere Henrique Leitão (Leitão, 2009). Foi um tempo de inovações, também sentidas ao nível da navegação, que permitiram um desenvolvimento em múltiplas frentes sem espaços de retorno no conhecimento de novas realidades. $\mathrm{O}$ conhecimento prático então transmitido de «boca em boca» tornara-se insuficiente. Gaspar Nicolas atuou como divulgador e formador do saber matemático ligado a esta nova realidade. $\mathrm{O}$ número enquanto entidade de medida impôs o seu estatuto e a aritmética foi vista como uma «escada» para alcançar outros saberes. Quando Nicolas afirma ser necessário no reino um livro de aritmética, podemos entendê-lo como uma denúncia à fraca escolarização dos portugueses e ainda, a auto valorização da sua obra. O ambiente nacional era propício à criação. Neste contexto, o Tratado da Pratica d'Arismetica nasceu em terreno fértil.

Neste estudo procuramos apresentar um enquadramento da obra e do autor na sua época. E neste ponto surgem algumas questões: à parte as dúvidas de D. Rodrigo, qual era o público visado pelo autor? Podemos ler as passagens na obra referentes ao esclarecimento de dúvidas na Casa da India sobre o cálculo dos impostos. De um modo geral, os assuntos expostos são, na sua maioria, temas que fazem parte de uma tradição em aritmética prática, como as regras de companhias, as baratas, as ligas da prata e do ouro. Contudo, o corpus aritmético português integra duas regras comerciais locais. Trata-se da regra de quarto e vintena e da regra da conta de Flandres. Estas duas regras têm a sua origem no comércio português com o Oriente e mostram bem a interação entre os saberes e a realidade envolvente através da presença de modelos aritméticos na vida económica.

O tratado de Nicolas, tendo sido a primeira obra de aritmética prática publicada em Portugal, interessou-nos averiguar que temas da matemática estão presentes nos conteúdos. Assim, observamos a presença de uma Matemática pensada para o comércio, tal como já referimos, a par com processos desligados do mundo mercantil, tais como os que se encontram associados à resolução de alguns problemas para determinar números. Outras práticas aparecem disfarçadas de temas mercantis mas visam trabalhar entes matemáticos. Podemos observar os exemplos dos mercadores que investem nas companhias mas desconhecem o que investiram ou os tempos nas companhias, que nos conduzem a sistemas lineares cuja resolução nos remete para conceitos algébricos que certamente o mercador comum não dominava.

$\mathrm{Na}$ época a que nos reportamos, a noção de plagiato não existia e, como referiria mais tarde Guiral Pacheco «comiam todos por mão alheia» (Pacheco, 1624, prologo). Contudo, colocou-se-nos a questão seguinte: Que obras matemáticas teriam inspirado Gaspar Nicolas na redação do seu tratado de aritmética prática? Encontramos resposta nas palavras do próprio autor quando refere Frey Lucas de Sam Francisco (Luca Pacioli) em 
múltiplas passagens da sua obra. A herança italiana no domínio da aritmética mercantil parece dominante tendo em conta o número avultado de obras produzidas. Contudo, as vias de transmissão da aritmética na Europa é um tema que deixa algumas questões em aberto e não podemos subestimar o legado das Espanhas com uma cultura multifacetada que marcou a produção científica e projetou-se para fora da sua fronteira. Não será de estranhar que a cultura dos reinos vizinhos chegasse também a Portugal.

\section{Gaspar Nicolas no enquadramento socioeconómico do seu tempo}

\section{A obra}

Como já referimos na Introdução, considera-se que o primeiro livro de Matemática impresso em Portugal foi o Tratado da Pratica d'Arismetica de Gaspar Nicolas, em 1519. Num livro dedicado à História das Matemáticas em Portugal, Francisco Gomes Teixeira (Teixeira, 1934, p. 98) reconhece o valor daquela obra afirmando ser o livro mais antigo consagrado em Portugal à Aritmética. Deste tratado existe um exemplar da primeira edição na Faculdade de Ciências da Universidade do Porto que em 1963, foi publicado em edição fac-similada pela Livraria Civilização do Porto e prefaciada pelo Professor Luís de Albuquerque. A edição de 1519 saiu da oficina de Germão Galharde'no dia 15 de Novembro de 1519, comemorando-se, no presente ano, 500 anos. No Tratado da Pratica d'Arismetica o prólogo ocupa as duas primeiras páginas. Seguem-se as tavoadas: Tavoada da prata, tavoada pequena e tavoada grande. Não há qualquer espaço com as funções de índice. Os temas encontram-se bem demarcados ao longo do texto, sem que este esteja dividido em capítulos.

\footnotetext{
${ }^{1}$ German Galharde foi um tipógrafo de nacionalidade francesa que se estabeleceu em Lisboa a partir de 1519 , adotando o nome Germão Galharte. Este tipógrafo imprimiu em Lisboa e em Coimbra. (http://tipografos.net/historia/gaillard.html (acedido em 01/10/2019))
} 


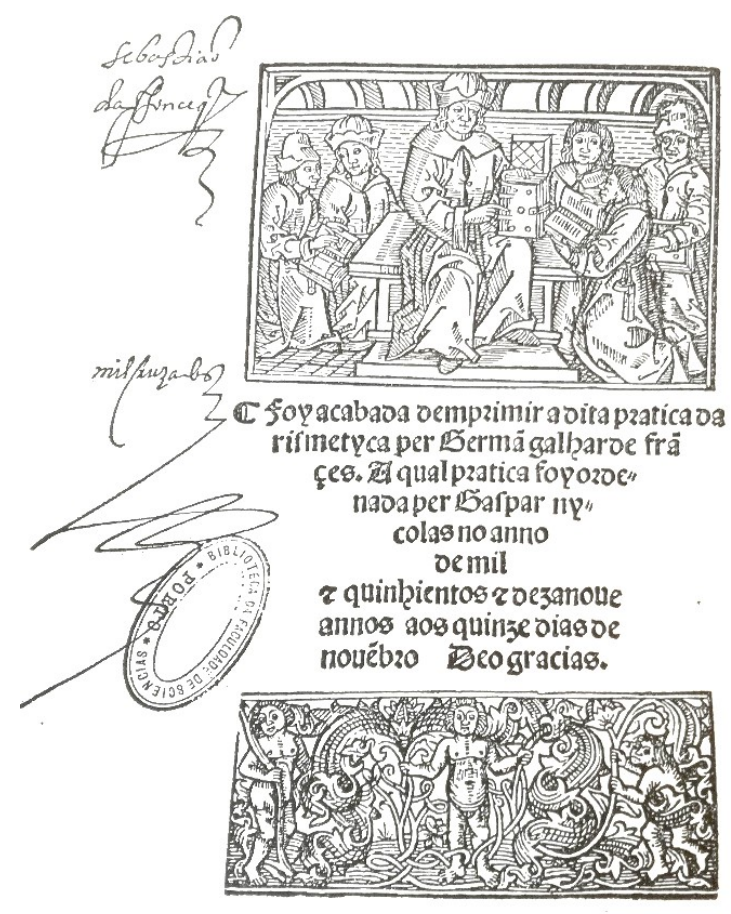

Fig.1 Colofão do Tratado da Pratica d'Arismetica

\section{O autor}

Sobre o autor os dados são escassos. Contudo pensa-se que viveu entre o último quartel do século XV e o segundo do século XVI. A. A. Marques de Almeida remete-nos para Luís de Albuquerque que admite a possibilidade de Gaspar Nicolas ser de origem judaica (Almeida, 1994, v. I, p. 79). Na nota bibliográfica presente na edição fac-similada de 1963, Luís de Albuquerque escreve,

"Nascido talvez em Guimarães, Gaspar Nicolas, cujos dados biográficos são escassos, tem o seu nome ligado aos aspectos científicos dos descobrimentos Portugueses, pois atribui-se-lhe parte activa na realização de tábuas náuticas." (NICOLAS, 1963, Nota sobre a obra e o autor de Luís Mendonça de Albuquerque)

Diogo Barbosa Machado (Machado, 1741-1759, t. II, p. 364) deu-o como natural de Guimarães e atribuiu-lhe a categoria de aritmético. O que sabemos de Gaspar Nicolas está ligado à obra que nos deixou. No prólogo do Tratado da Pratica d'Arismetica o autor 
refere as suas ligações à cidade de Guimarães onde encontrou, numa dada ocasião, D Rodrigo, Conde de Tentúgal ${ }^{2}$ que aqui aparece no papel de um mecenas com interesse pela Aritmética, segundo nos relata Nicolas.

"E porque Senhor, nã ha muytos tẽmpos que eu vi ha V. S. em Guimaraẽs e me fez algũuas preposições e pregũtas nesta arte de Arismetyca me ficou dahy hũu desejo de servir V. S..” (NICOLAS, 1963, PROLOGO)

\section{As motivações}

O habitual discurso de agrado ao mecenas conjuga-se com o elogio à Aritmética, entre «as outras artes»: «Arismetica pella qual se alcança as outras artes (...) pera viir o propio conheçymento das sciençias e artes em particular. Convem peso e medida numero...» (Nicolas, 1963, prologo). O reconhecimento da necessidade de um livro de aritmética no reino, dado o elevado volume de negócios, com a Índia, a Pérsia, a Arábia e a Etiópia e outros domínios mais próximos do reino, é ainda um ponto de destaque no discurso do autor.

"Muy Manifyco Senhor, por ser cousa muy neçessaria nestes regnos e senhorios de Portugal por bem de em eles floreçerem os tratos das mercadorias da India e Persia e Arabia e Thyopia e outras partes mays chegadas a nos e os tratadores multiplicarem nos dytos Reynos me moveo ha fazer e cõpor este breve tratado de Arismetyca." (NICOLAS, 1963, PROLOGO)

Gaspar Nicolas escreveu um tratado de aritmética prática, com um estilo muito claro, «per estyllo muy claro pera que facilmẽte possa aproveytar e aproveyteahos que ha virem e lerẽ» (Nicolas, 1963, prologo). Uma leitura da obra realça o caracter breve e imediatista do seu autor, quer em termos de introdução aos temas, quer na prática algorítmica, como veremos mais à frente.

O Tratado da Pratica d'Arismetica foi muito popular no reino de Portugal dado que, sem contar com a edição de 1519, foi impresso nos séculos XVI, XVII e XVIII (apenas uma edição), num total de nove vezes (Nicolas 1963, Nota sobre a obra e sobre o autor de Luís de Albuquerque), o que demonstra um certo reconhecimento, agrado pela obra e utilidade da mesma na formação, tendo sido considerado, por Gomes Teixeira (Teixeira, 1934, p. 98), como já afirmámos, «um excelente manual de Aritmética prática, muito claro e simples na exposição das doutrinas, sem teorias, que certamente prestou bons serviços no século XVI».

No sentido de valorizar a sua obra, Nicolas sublinha o papel da aritmética, «senhora das outras Ciências», implicada nas relações do saber matemático com o real, através de

${ }^{2}$ O Conde de Tentúgal era D. Rodrigo de Melo (1488-1545) também $1^{\circ}$ Marquês de Ferreira. Era filho de D. Álvaro (filho dos segundos Duques de Bragança) e de sua mulher, D. Filipa de Melo. Pressume-se que nasceu em Castela durante o exílio do seu pai. Foi agraciado com o título de Conde de Tentúgal por D. Manuel em 1504 (Almeida, 1994, v. I, p. 77). 
uma noção poderosa: a noção de número como «medida», ou seja, «medir» tudo o que é «material».

\begin{abstract}
"He neçessario que sejamos inclynados a ella como senhora das outras sciençias porque ella abre as portas do entendimento e imprime huũ desejo de natural especulaçam pera viir na realidade das cousas que della dependem como seja verdade que pera viir o propio conheçymento das sciençias e artes em particular: Convem peso e medida número." (NICOLAS, 1963, PROLOGO)
\end{abstract}

Marques de Almeida caracteriza a Aritmética do dealbar da Época Moderna como uma disciplina cuja aceitação social não suscitou qualquer contestação, que sobreviveu porque se tornou necessária e se comportou como um sistema de comunicação (Almeida, 1994, v. I, pp. 49, 50). Foi com base na «necessidade da aritmética», como o refere no prólogo, que Gaspar Nicolas alicerçou o seu tratado e abriu o caminho a uma vulgarização do algoritmo na forma de cálculo escrito e ferramenta essencial na construção de modelos que viriam a servir o saber matemático e a prática mercantil.

Os tratados de aritmética prática, escritos em Portugal na época de Quinhentos, enquadram-se numa categoria de obras onde, para além da divulgação dos números indoárabes, aparece um conjunto de problemas e as suas resoluções. Estes problemas focam temas comerciais, associados a regras de cálculo, tais como as baratas, as companhias e a regra de quarto e vintena. Porém, existem outros enunciados de temas recreativos que podemos traduzir e resolver com recurso aos elementos da álgebra. Gaspar Nicolas, ao conceber o seu tratado não foge a esta tradição. É reconhecida a importância dos tratados de aritmética no desenvolvimento do saber matemático de épocas vindouras. Aos textos essencialmente práticos associavam-se temas ligados ao «fazer matemática pelo gosto de o fazer» através de assuntos à partida desligados do mundo mercantil. Interessa-nos ver como Gaspar Nicolas divulgou este saber na sua época em Portugal.

\title{
3. Estrutura do tratado e temas abordados: matemática comercial versus matemática "pour elle même"
}

Gaspar Nicolas inicia o tratado com a apresentação das bases ou seja, dos números: «Primeiramẽte te he neçeesario cõhecer as letras e despoys de conheçidas saber numerar cõvẽ asaber cõhecer estas mesmas letras quãto vallẽ» (Nicolas, 1963, f. 1). As dez «letras» da aritmética são os algarismos de 0 até 9 . De seguida trata as cinco operações aritméticas básicas: «numerar, conta de assomar, conta de demenuir, conta de multiplicar e repartir» (Nicolas, 1963, ff. 1f-10f). Segue-se a regra de três, as regras de companhias e as regras de quarto e vintena. Todas estas regras são necessárias ao mercador. Pela variedade dos problemas exibidos, bem como das referências à Casa da Índia, somos levados a crer que era um assunto de destaque na obra. Teria sido por acaso ou uma necessidade para os mercadores e a administração do reino? Nos enunciados propostos está bem claro o papel do imposto ligado à prática do quarto e vintena na economia nacional, daí deduzir-se o papel de destaque na obra. 
Nicolas passa às operações com quebrados e à regra da conta de Flandres, às progressões, deixando para depois a regra de baratas. Parece haver uma vontade de intercalar temas de aritmética mercantil com assuntos matemáticos desligados do ambiente dos negócios. O seu tratado inclui ainda um conjunto de problemas que abordam as regras enunciadas, numa secção denominada «Números e Perguntas». Trata-se, não só, de um conjunto de enunciados para consolidação das regras mas também um meio de abordar outros temas.

Um assunto singular na obra é o tema «Geometria». Nas últimas páginas aparecem os problemas da liga da prata. Vejamos de mais perto algumas temáticas presentes.

\section{Números e operações básicas da aritmética}

O Tratado da Pratica d'Arismetica contem, nos primeiros fólios, as tabuadas pequena (de 1 até 10) e grande (de 11 até 30). Seguem-se as cinco operações aritméticas básicas: «numerar, conta de assomar, conta de demenuir, conta de multiplicar e repartir» (Nicolas, 1963, ff. 1f-10f), para números inteiros e no fólio 19 para números quebrados.

$\mathrm{Na}$ obra, os números são entidades de «medida» estando ausente a sua anterior «figura» especulativa, que se perdeu no mundo mercantil, dado que, a aritmética comercial assentava nas técnicas de cálculo. De que números se tratava? Dos números inteiros, exceto o zero, representados no sistema decimal indo-árabe; dos números fracionários (quebrados), da forma $\frac{a}{b}$, tal que $a$ e $b$ são números inteiros naturais e $0<a<b$; dos números mistos, representados por $a \frac{b}{c}$ tal que $a, b$ e $c$ são inteiros naturais e $a>0$ e $0<b<c$. Estes números assim escritos correspondem a $a+\frac{b}{c}$.

Uma característica de Nicolas foi insistir nos cálculos numéricos sem mencionar qualquer unidade destacando a prática do algoritmo. Vejamos um exemplo na «conta de assomar»:

"Enxẽpro digo que quero assomar .2345676. e mais .497630. e mais .46987. e mais .2739. e mais .947. e mais .84. e mais .9. digo que assentes como aqui esta afegurado e começaras sempre da mão dereita pera a mão esquerda e nã faz mais começar em çima que em baxo." (NICOLAS, 1963, f. 2f).

Para a subtração o caminho a seguir é semelhante e a regra resume-se ao procedimento seguinte

"Se quiseres demenuir huũa conta poeras primeyramente assoma maior em çima e de baxo desta poeras aquella quantidade que quiseres tirar. E começaras sempre a maão dereita como em assomar. " (NICOLAS, 1963, f. 3f)

A ausência de unidades é reforçada noutros algoritmos tais como o de multiplicar em cruz: 
"Se queres saber outro modo de multipricar mas que quer grande memoria e chamasse multipricar em cruz que say toda a soma em huũa regra teras este modo tomar as letras de çima e multipricallas cõ a de baxo e assentras as unidades e teras as dezenas na cabeça e depois multipricaras com esta mesma de çima a outra mesma letra de baxo e ajuntaras as dezenas que levavas com esta mesma multipricaçam e tellos a todos na cabeça sem assentar nada. Ora tomaras a outra letra de çima e multipricallaas em cruz a de baxo e com a multipricaçã que fazer ajuntaras os que dantes tinhas e todos juntos veras quantos sam. E poeras hos que passarem das dezenas ao pee e os outros guardaras. Ora multiprica a mesma letra que agora multipricaste cõ a outra de baxo convem a saber multiprica huũa com a outra e com a multipricaçam ajuntaras hos que levavas e assoma ho que todo fezer e assentalloas na derradeira .s. escontra a mão esquerda segundo a usanssa e modo de multipricar." (NICOLAS, 1963, F. 6)

Todas as operações enunciadas apelam ao cálculo mental, sobretudo o «multiplicar em cruz» quando o autor afirma «...outro modo de multipricar mas que quer grande memoria» (Nicolas, 1963, f. 6). Este algoritmo pressupõe uma decomposição dos números e a utilização do que hoje designamos por propriedade distributiva da multiplicação em relação à adição. Para traduzirmos o que foi realizado e uma certa arrumação dos resultados nas respetivas classes e ordens, vamos esquematizar o algoritmo proposto, ou seja, efetuar o produto $34 \times 23$, considerando fatores escritos na forma da soma de dois números $(30+4)(20+3)$

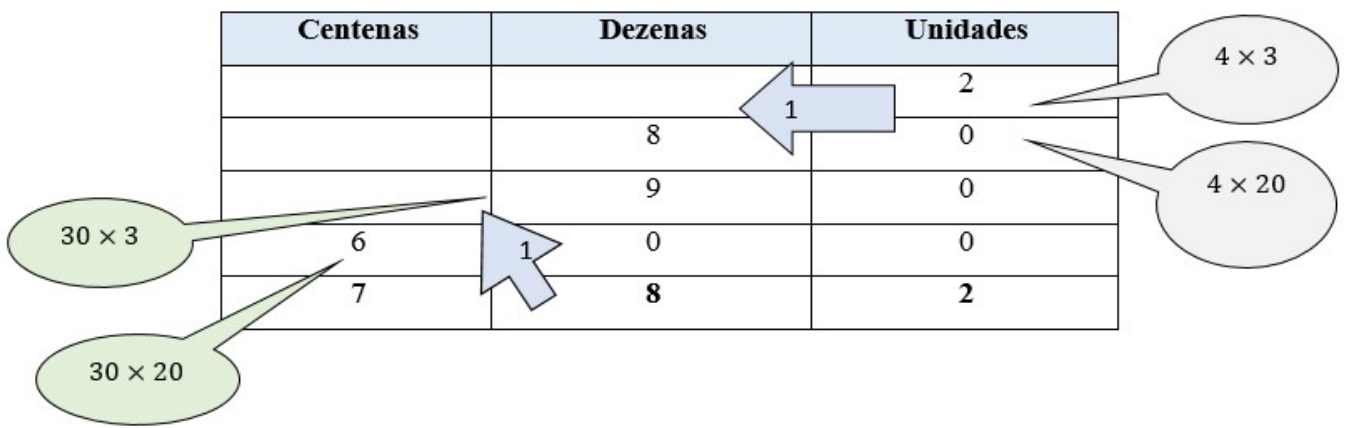

Figura 2: Um exemplo de multiplicar em gelosia por Gaspar Nicolas (Nicolas, 1963, f. 7 f)

O resultado 782 obtém-se somando os valores das colunas relativas a unidades, dezenas e centenas.

Uma outra maneira de multiplicar é a gelozia ou graticola. A figura que aqui apresentamos é de Nicolas, para o produto de 769 por 496. 


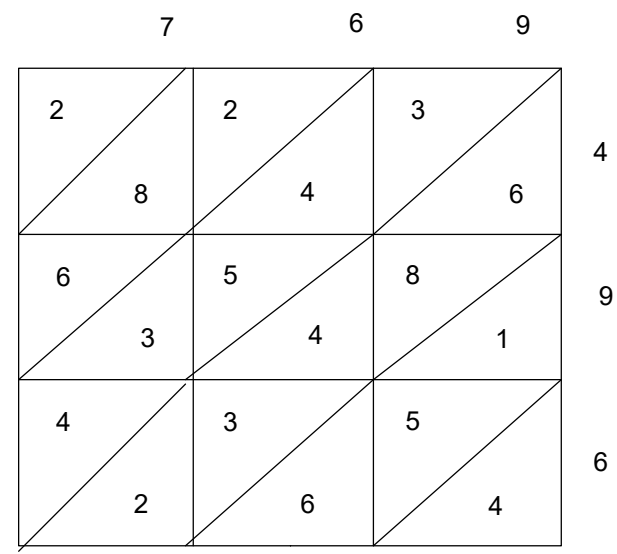

Soma 381424

Figura 3: Um exemplo de multiplicar em gelosia por Gaspar Nicolas (Nicolas, 1963, f. 7 f)

Este método é muito simples e prático, acredita-se que facilitasse os cálculos aos mercadores. Este procedimento está na base da conceção das varas de Neper e reduz a multiplicação a procedimentos aditivos.

A divisão era um processo bastante elaborado e conhecido como «dividir em galera». Um exemplo deste algoritmo é-nos descrito de forma minuciosa por Gaspar Nicolas e acompanha-o o esquema seguinte

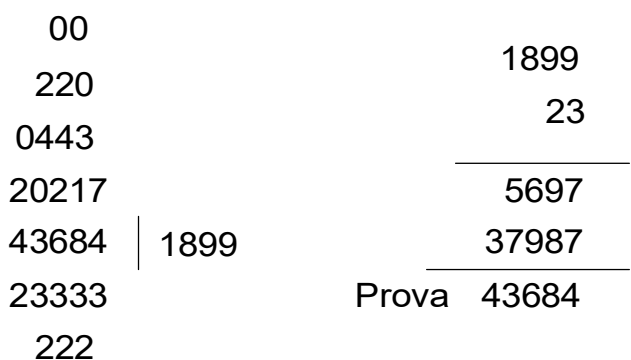

Figura 4: Dividir 43684 por 23 usando a «divisão em galera» (Nicolas, 1963, f. 9 v)

Este procedimento explica-se nos passos seguintes sempre com recurso à propriedade distributiva: 
$43-1 \times 23=43-23=20$

$206-8 \times 23=206-8 \times(20+3)=206-160-24=46-24=22$

$228-9 \times 23=228-9 \times(20+3)=228-180-27=48-27=21$

$214-9 \times 23=214-9 \times(20+3)=214-180-27=34-27=7$

\section{A regra de três}

Nos fólios 11 e 12 da obra, depois das operações básicas com números inteiros, aparece a «regra de ouro» dos mercadores, referimo-nos à regra de três. A expressão «regra de três» pressupõe que, a partir de três números dados, um dado procedimento vai permitir encontrar um quarto número. Esta regra está na base de outros algoritmos, nomeadamente os de falsa posição a par com outras regras também dirigidas para os negócios, tais como as companhias e baratas. Será este enquadramento obra do acaso ou uma intenção do autor, dado o reconhecido do papel da regra na base das operações comerciais? Nicolas começa por abordar a regra de três para os números inteiros e subdivide-a em cinco variantes: regra de três chaã; regra de três com tempos; regra de três com tempo à razão de tanto por cento; regra de três chaã em que a da metade é o partidor; regra de três em que a derradeira é partidor. O princípio básico enunciado é o seguinte: «...a principal regra de tres he desta maneyra multipricar a segunda (b) com a terceyra (c) e repartir com a primeyra (a)» (Nicolas, 1963, f. 11 f), o que denota um manifesto entendimento do principal princípio da regra, uma vontade de simplificar e de abreviar (a---b---c) logo o quarto número será $d=\frac{b c}{a}$. Esta definição é a usual. Por exemplo, encontrámo-la noutros autores, como Chuquet que descreve este mesmo algoritmo: «O modo da regra é o seguinte: multiplica o terceiro número pelo segundo e depois divide pelo primeiro» ${ }^{3}$.

O primeiro exemplo enunciado por Nicolas é o seguinte: «...se .70. valẽ .97. que valeram .240. a este mesmo respeyto» (Nicolas, 1963, f. 11 f). Este é um tipo de enunciado muito comum nas aritméticas práticas e centra-se em dois aspetos: o primeiro é o uso do «se», o segundo é a apresentação dos dados desembaraçando-se de todas as unidades para destacar a regra, tal como já referimos, e assim, apresentar como prioridade o funcionamento do algoritmo. A resposta é imediata: «...multiprica .97. por .240. e faras .23280. e parteos por .70. e virteam em partiçam .332. e $\frac{4}{7}$ e tantos diras que ganham .240. » (Nicolas, 1963, f. 11 f). O autor enaltece o algoritmo em detrimento das unidades que, certamente estão presentes na sua memória.

Quando a regra de três contém o tempo então

\footnotetext{
${ }^{3}$ Chuquet citado por Marie-Hélène Labarthe «Le mode de cette règle est le suivant: multiplie le troisième nombre par le second et puis divise par le premier» (Labarthe, 2004, vol. I, p. 123).
} 
“...multiprica os tempos com a primeyra e este sera teu partidor e pera saberes qual he a partiçam multiprica ho ganho com a terceira e com os tempos que esta de baixo della e parte pelo partidor e o que vier tanto ganha." (NICOLAS, 1963, f. 11f)

Uma característica dos tratados portugueses de aritmética é a vulgarização da noção de percentagem ${ }^{4}$. Deste modo, podemos observar o seu uso na regra de três com tempo à razão de tanto por cento.

“...se faz desta maneyra multipricar hos tempos com o tanto por .100.. E com a primeyra e este sera ho teu partidor e pera saberes qual he a partiçam multipricaras ha segũda com ha terçeyra e com os tempos e com a rezam de tanto por.100. e aquilo que te sair partiras polo teu partidor." (NICOLAS, 1963, f. 11v)

Gaspar Nicolas enuncia uma «regra de três chaã em que a da metade é o partidor». A introdução é breve: «...se com .20. ganho .6. com quantos ganharey .30. » (Nicolas, 1963, f. $12 \mathrm{f}$ ). $\mathrm{O}$ autor propõe um algoritmo que designa por regra geral: «tem regra jeral multiprica sempre as dos cabos e parte pella da metade» (Nicolas, 1963, f. 12 f). Podemos pensar na ordenação dos números em jogo

$$
a-b \longrightarrow c
$$

Os «cabos» são $a$ e $c$. O «da metade» é o valor central, ou seja, $b$. São propostos dois problemas. No primeiro enunciado Nicolas coloca a seguinte questão: se $a$ vale $b, c$ quantos valerão? Na segunda questão o sentido é outro: se com $a$ ganho $b$, com quantos ganharei $c$ ? Pensando em termos de relação entre $a, b$ e $c$ temos, na primeira questão, para o número $d$ desconhecido:

E na segunda,

$$
b c=a d \Leftrightarrow d=\frac{b c}{a}
$$

$$
a c=b d \Leftrightarrow d=\frac{a c}{b}
$$

Para finalizar a regra de três com inteiros, Nicolas exibe a «regra de três em que a derradeira é partidor». A esse respeito afirma o autor:

\footnotetext{
${ }^{4}$ Ainda que a noção de percentagem seja conhecida em alguns tratados escritos nas cidades italianas, não é contudo, um assunto vulgarizado. Nos reinos de Espanha estão presentes problemas de «companhias» que envolvem o «tanto por cento» nos tratados de Juan Ortega, Juan Andrés e Joan Ventallol. Os aritméticos portugueses vulgarizaram a «percentagem» nos múltiplos problemas enunciados e resolvidos com as regras de companhias, sem contudo traduzirem o imposto de quarto e vintena por uma percentagem. É Guiral Pacheco que «transforma» o cálculo do quarto e vintena na aplicação de um «tanto por cento», no seu tratado Flor da Arismetica Necessaria, publicado em 1624
} 
"Outra regra de três em que ha derradeira he ho partidor e a segũda com a primeira multipricada hũa pella outra he a partiçam assy como se te preguntassem quãto ho alqueire de trigo valia a 60 . reaes me davam huũ pão por .2. reaes que pesava.7. onças veyo ho trigo a valer .48. pregunto de quantas onças me daram huũ pão e se o saber quiseres multiprica .7. vezes .60. e faras .420. estes parte por. 48. e vem .8. onças $e \frac{3}{4}$ e tantas onças te daram valendo ho trigo a .48 . reaes e por esta regra podes fazer quantas quiseres. E oulha como aquy esta feyto.' (NICOLAS, 1963, f. 12f)

$\mathrm{O}$ algoritmo conduz-nos a um esquema, que o autor não exibe

$$
a-b
$$

A regra consiste em efetuar o produto $a \cdot b$ que é dividido por $c$, o «derradeiro», como o designa Nicolas. No exemplo proposto, os 2 reais relativos ao custo do pão vão manter-se quando baixa o preço do alqueire do trigo contudo, o peso do pão $b$ é alterado na razão $\frac{a}{c}$ Assim temos o «novo peso», $d$, como consequência da descida do alqueire de trigo de $a$ para $c$ dado por

$d=b \times \frac{a}{c}$

No reconhecimento de uma base do saber matemático assente na regra de três Gaspar Nicolas situa este tema entre os primeiros temas expostos no seu tratado. Ainda que a regra de três possa assumir diferentes designações, como o referimos atrás, Gaspar Nicolas optou pela expressão «regra de três» em vez de «regra das proporções» ou «regra dourada», pelo que foi seguido pelos aritméticos que o sucederam, Ruy Mendes e Bento Fernandes, quando abordam temas mercantis que dão sentido à aplicação da regra.

\subsection{Matemática Comercial}

\section{Regras de companhias}

À semelhança de outras obras para o mesmo fim, a grande vocação do Tratado da Pratica d'Arismetica era essencialmente comercial. Neste saber ligado à prática mercantil, a regra de três dominava os procedimentos a utilizar, tal como afirmamos na secção anterior. Contudo a partir desta regra outras, mais sofisticadas, foram enunciadas. Por exemplo, a regra de três estava na base das regras de companhias.

A definição de «companhia» está assente numa associação de homens com vista a obter lucros. Uma prova da divulgação e popularidade das companhias comerciais podemos obtê-la no Tratado da Pratica d'Arismetica. Os problemas de partilha de lucros seriam uma prática corrente entre todos os envolvidos nas transações comerciais e disso são testemunho os enunciados que visam determinar a distribuição de ganhos pelos associados. As regras de companhias figuram nos fólios 12, 13, 14 e 15 do tratado de Nicolas e este aritmético inicia o assunto com a regra de companhias chaãs: 
"Regra de cõpanhias chaãs faras desta maneira assomaras a quãtidade que cada huũ dos cõpanheiros poem toda em huũa soma e depois que o teveres assomado saberas que esta soma he o teu partidor e pera saberes qual ha de ser a tua partiçã multiprica o ganho que ganharã pelo que cada huũ poos e o que sair da multiplicação sera tua partiçam." (NICOLAS, 1963, f. 12v)

Dada a «regra geral», a prática é composta por um conjunto de problemas como este que enunciamos

“...sam .3. companheiros e fezeram companhia em esta maneira .s. que ho primeiro pos .74. cruzados e o outro pos .89. e outro pos .93. e ganharam todos tres .62. cruzados. Ora eu demando quanto vem há cada huũ tirãdo o cabedal fora. " (NICOLAS, 1963, f. 12v)

Pretende-se determinar os ganhos de cada mercador: «....assomaras .74. e .89. e .93. e faras .256. este he ho teu partidor» (Nicolas, 1963, f. $12 \mathrm{v}$ ). Este procedimento corresponde à soma dos investimentos dos envolvidos na companhia ${ }^{5}$, ou seja, em linguagem atual,

$$
\sum_{j=1}^{3} i_{j}=256
$$

Sendo $i_{j}$ o investimento da cada investidor. Para determinar o ganho de cada um:

“...pera saberes qual he a partiçã multiprica.62. que ho ganho de todos por .74. que he a quantidade que ho primeiro pos e faras .4588. estes parte por .256. e vem da partiçam .17. e ficam .236. por partir." (NICOLAS, 1963, f. 12v)

As companhias poderiam ter outras variáveis em jogo tais como o tempo na companhia. Era importante conceber uma regra que salvaguardasse os interesses de todos os participantes, que tornasse o negócio realizado com clareza para não dar lugar a queixas. Sobre a entrada do «tempo» diz-nos Nicolas: «...As companhias cõ tẽpos se fazem assy desta maneyra. Multiprica os tẽpos cõ ho que cada hũ poẽ e entã seram assy como as primeyras» (Nicolas, 1963, f. 13 f).

Sem entrar em detalhes sobre a variedade de problemas, as soluções para estes casos, relativamente aos ganhos são dadas por expressões do tipo,

${ }^{5}$ Se forem $n$ associados, vamos designar por $i_{j}(1 \leq j \leq n)$ o investimento de cada um e por $g_{j}$ os respetivos ganhos e temos as condições

$\sum_{j=1} g_{j}=g \quad$ e $\quad \frac{g_{1}}{i_{1}}=\frac{g_{2}}{i_{2}}=\cdots=\frac{g_{n}}{i_{m}}=\frac{g}{\sum_{j=1}^{n} i_{j}}$ 


$$
g_{j}=\frac{g i_{j} t_{j}}{\sum_{j=1}^{3}\left(i_{j} t_{j}\right)},(1 \leq j \leq n)
$$

onde os $t_{j}(1 \leq j \leq n)$ representam os tempos de cada sócio na dita companhia, $g$ é o ganho na companhia.

A noção de percentagem está muito presente na Pratica de Nicolas e os enunciados das companhias não são exceção. A «regra de companhias com tempos e com tanto por cento» visa determinar os ganhos de cada um dos envolvidos na companhia, tal como afirma o autor:

"Companhias cõ tempos e tantos por .100. se fazẽ desta maneyra assy como te dixessem sã .2. cõpanheiros e fezerã cõpanhia nesta maneira que ho primeiro pos .72. cruzados e servio .4. meses a rezam de .3. por çento e o outro pos .57. e servio .5. meses a rezam de .6. por .100. e ganharã ambos .84. cruzados.Pregũto quanto vem a cada huũ." (NICOLAS, 1963, f. $14 \mathrm{v})$

Segundo o enunciado proposto temos $\left\{\begin{array}{c}i_{1}=72, i_{2}=577 \\ t_{1}=4, t_{2}=5 \\ c_{1}^{\prime}=3, c_{2}^{\prime}=6\end{array}\right.$

Os resultados pretendidos vêm pela regra de companhias chaãs: «...Faze agora como cõpanhias chaãs e diras sam .2. companheyros ho primeyro pos $.864^{6}$. e o outro meteo $.1710^{7}$. e ganharam ambos .84. cruzados demãdo quanto vem a cada hũ» (Nicolas, 1963, f. $14 \mathrm{v})$. O valor de cada ganho, podemos encontra-lo usando a notação que temos vindo a adotar, tendo-se

$$
g_{j}=\frac{g i_{j} t_{j} c_{j}^{\prime}}{\sum_{j=1}^{2}\left(i_{j} t_{j} c_{j}^{\prime}\right)}
$$

$\mathrm{O}$ conjunto de problemas sobre companhias terminam com um enunciado «menos natural» designado «Outras companhias» e que vai conter como incógnitas um dos ganhos e os investimentos de cada um dos três envolvidos na companhia.

Se te dixessem tres companheiros fezeram cõpanhia em esta maneira. Que meteram antre todos .736. cruzados e ganharam .254. e ho primeiro veio de ganho .43. cruzados e ao segundo veio .75. Ora eu demãdo quãto vem ao terceiro e quanto meteo cada huũ na cõpanhia. (NICOLAS, 1963, f. 15f)

Temos os dados seguintes:

${ }^{6} 864=72 \times 4 \times 3=i_{1} t_{1} c_{1}^{\prime}$

${ }^{7} 1710=57 \times 5 \times 6=i_{2} t_{2} c_{2}^{\prime \prime}$

RBHM, Vol. 19, n 38, p. 105-137, 2019 
$\left\{\begin{array}{c}i_{1}+i_{2}+i_{3}=736 \\ 43+75+g_{3}=254\end{array}\right.$

O autor propõe determinar $g_{3}, i_{1}, i_{2}, i_{3}$.

«...assoma .43. cruzados do primeiro e.75. do segundo e faras .118. tira os de .254 . que foy o ganho e ficam .136. » (Nicolas, 1963, f. 15 f) . O primeiro cálculo a efetuar dá o valor $g_{3}=254-118=136$. Quanto aos investimentos individuais: «...se .254 . cruzados sam ganhados com .736. com quantos seram ganhados .43. cruzados que veio ao primeiro» (Nicolas, 1963, f. 15 f). Vem então a resposta: «....se ho saberes quiseres multyprica .736. por .43. e faras .31648. parte os por .254. e vẽ em partiçam .124. » (Nicolas, 1963, f. 15 f) . De um modo semelhante, determinam-se os outros valores. O algoritmo dá-nos cada investimento $i_{j}(1 \leq j \leq 3)$

$$
i_{j}=\frac{\left(\sum_{j=1}^{3} i_{j}\right) g_{j}}{g}
$$

Nos enunciados expostos deparamo-nos, com outras «incógnitas», tais como os investimentos individuais ou tempos na companhia entendidos como questões «menos naturais» e que, visam sobretudo, uma vontade de manipular os entes matemáticos pondo em jogo quantidades proporcionais. Há uma manifesta intenção de estender a Matemática para o comércio a um saber matemático emancipado do real.

\section{Os «baratos»}

Desde o fim da Idade Média que os «baratos» estão incluídos nas transações comerciais nos países mediterrânicos. Os «baratos» ${ }^{8}$ fazem parte de um sistema complexo de compra e de venda utilizada pelos mercadores, particularmente quando estes percorriam grandes distâncias para negociar.

A regra de baratas aparece como resposta a uma falta de liquidez de capital, dado que, numa transação comercial, permite trocar um produto por outro (barata simples) ou ainda, uma parte de um produto por dinheiro e outra parte por outro produto (barata composta). M. Labarthe (Labarthe, 2004, v. II, pp. 262, 263) refere um primeiro traço dos «baratos» na Península Ibérica no manuscrito catalão do século XIV, Libre de conexenses de spícies e drogues e de avissaments de pessos, canes e massures de diverses terres. Também no Libro de arismética que es dicho alguarismo escrito entre 1393 e 1400 aparece um enunciado de um problema de «baratos»: «Son dos omes e quieren trocar el uno com el outro. El uno tiene paño y el outro pimienta...» (Caunedo, 2000, p. 157). Outras obras posteriores referem o assunto tais como os tratados de Santcliment, Ortega e Ventallol.

A prática de baratas está bem presente no Tratado da Pratica d'Arismetica, à semelhança do que se verifica noutros tratados da mesma natureza que foram aparecendo

\footnotetext{
${ }^{8}$ Designação utilizada por Gaspar Nicolas para esta regra
} 
um pouco por toda a Europa. Segundo M. Almeida foi uma prática que persistiu devido à baixa velocidade da circulação monetária, a partir de 1530 e ao disparo por toda a Europa da subida dos preços e da inflação (Almeida, 1994, v. I, pp. 264, 265).

Gaspar Nicolas apresenta-nos quatro problemas das regras de baratas. No primeiro enunciado há uma referência à regra de três chaã e Nicolas tece o seguinte comentário: "Ysto nam he outra cousa se nam regra de tres chaã» (Nicolas, 1963, f. 38 f). Um dos enunciados propostos e que ilustra bem o tipo de produtos comercializados é o seguinte:

"Dous baratam cravo e canella a canella val a dynheyro contado .5. cruzados e ha barato se conta a .6. cruzados e quer huũ terço a dinheyro da quyllo que valer a baratoe os dous terços é cravo e o cravo val a dinheiro .17. cruzados demãdo que se devera meter a barato." (NICOLAS, 1963, f. 38f)

Para o caso descrito, temos os dados seguintes:

-o preço de cada um dos produtos em dinheiro, na unidade considerada: $p_{1}, p_{2}$

-o preço de cada um dos produtos na barata, na unidade considerada: $p_{1}^{\prime}, p_{2}^{\prime}$

Os dados do enunciado levam-nos a considerar

$\left\{\begin{array}{l}p_{1}=5 \\ p_{1}^{\prime}=6 \\ p_{2}=17\end{array}\right.$

Pretende-se determinar $p_{2}^{\prime}$, o preço do cravo no barato.

A condição imposta visa tomar um terço da canela em dinheiro daquilo que valer no barato e os restantes dois terços em cravo. Para o efeito Nicolas propõe que «...sempre tira a parte que elle quer aver em dinheyro do seu barato e tyra do seu cabedal.» (Nicolas, 1963, f. 38 f).

Ou seja, calcula-se um terço de $6\left(\frac{p v_{1}}{3}=2\right)$; e retira-se de $6:\left(p_{1}^{y}-\frac{p_{1}^{\prime}}{3}=4\right)$.

De seguida tira-se 2 de 5: $p_{1}-\frac{p_{1}^{r}}{3}=3$. A regra de três chaã é aplicada (3----4----17)

$$
p_{1}-\frac{p_{1}^{\prime}}{3}---p_{1}^{\prime}-\frac{p_{1}^{\prime}}{3}---p_{2} \text { e } p_{2}^{\prime}=22 \frac{2}{3}
$$

Existem outros enunciados que conduzem a aplicações mais básicas da regra de baratas. Por exemplo, um primeiro mercador propõe um preço do seu produto (na unidade considerada) na barata que, será mais alto que o preço a dinheiro inicialmente previsto. $\mathrm{O}$ segundo mercador deve poder responder a esta proposta, sobreavaliando também o seu produto e de tal modo que os preços na transação estabeleçam um equilíbrio na troca efetuada. Assim, sendo

-o preço de cada um dos produtos em dinheiro, na unidade considerada: $p_{1}, p_{2}$ -o preço de cada um dos produtos na barata, na unidade considerada: $p^{\prime}{ }_{1}, p_{2}^{\prime}$ Pretende-se calcular o valor de $p_{2}^{\prime}$ de tal modo a que o negócio seja equilibrado para os dois mercadores. Pela regra de três temos 
O valor de $p_{2}^{\prime}$ é obtido segundo as relações de proporcionalidade: $p_{2}^{\prime}=\frac{p_{1} p_{1} p_{2}}{p_{1}}$

O tratado de Nicolas é pobre em problemas sobre os «baratos» comparativamente aos tratados de aritmética de Ruy Mendes e de Bento Fernandes escritos posteriormente. Bento Fernandes chega mesmo a propor uma regra de baratas pela «regra da cousa» em (Fernandes, 1555, f. 44 f).

\section{Regras da liga da prata e da liga do ouro}

Os problemas de «misturas» fazem parte, desde longa data, dos saberes matemáticos. Este tema está ainda presente no Liber abbaci, no Summa de Pacioli e em várias aritméticas escritas na época da Renascença na Península Ibérica, tais como os tratados de Santcliment, Ventallol, Ortega e Juan Andrés. Interessa-nos sobretudo, o que no diz Gaspar Nicolas sobre este tema.

Para esse efeito comecemos por referir a moeda-mercadoria que é aquela que tem um valor intrínseco igual ao seu valor monetário (Fonseca, 2010, p. 18). Este conceito baseia-se na ideia de que a economia monetária se desenvolveu a partir de uma economia de troca direta, onde as moedas teriam um valor igual ao das mercadorias. Os metais apresentavam qualidades que contribuíram para que a moeda tivesse características tais como: a divisibilidade, a homogeneidade e a durabilidade. A prata e o ouro são metais preciosos usados nas transações comerciais e apresentam-se em peças compostas por uma parte do metal precioso, ouro ou prata, e de outra parte de um metal de valor reduzido, de um modo geral cobre. As peças assim compostas apresentam uma «mistura» de metais que têm associados alguns elementos numéricos tais como o «peso», a «lei», a «fineza». Nas aritméticas portuguesas, as regras de prata e de ouro remetem-nos para uma realidade ligada ao fabrico de moeda ou de lingotes com metais preciosos e onde alguns conhecimentos em aritmética eram necessários. As atividades ligadas à produção monetária são de uma importância fundamental na vida económica da época.

Gaspar Nicolas dedica um apêndice da sua obra à liga da prata. Logo no início temos a afirmação seguinte: «Agora te quero mostrar a liga da prata em Portugall» (Nicolas, 1963, f. i f), o que nos leva a crer que o assunto prende-se com a realidade nacional. Nicolas não apresenta qualquer divisão tipológica para a liga da prata mas antes, um numeroso conjunto de enunciados. Quais são as incógnitas dos enunciados exibidos? A fím de facilitar a descrição e análise dos problemas propostos vamos considerar a nomenclatura seguinte para as ligas da prata/do ouro:

$P$-peso do metal em marcos

$F$-peso da prata/ouro (fineza da prata/fineza do ouro)

$C$-peso do outro metal pouco valioso

$L$-lei da prata/lei do ouro

Para a peça de metal é válida a relação seguinte: $P=F^{*}+C$. A lei, $L$, permite avaliar a quantidade de metal precioso na liga (para a prata $0 \leq L \leq 12$, para o ouro $0 \leq L \leq 24$ ). Na liga da prata se $L=12$ então $F=P$, desde que ambos estejam na 
mesma unidade de peso. O quociente $\frac{\boldsymbol{F}}{\mathbf{P}}$ é proporcional à lei, $L$ (as unidades de medida são diferentes para a prata e para o ouro), temos $F=\frac{L P}{12}$ (ou $F=\frac{L P}{24}$ na liga do ouro), onde o quociente $\frac{F}{p}$ é igual a $\frac{L}{12}$ e dá a proporção de metal fino (prata) presente na liga. Se o metal precioso é o ouro, $L=24$ e o quociente $\frac{L}{24}$ que dá a proporção do ouro na liga.

Nos problemas propostos por Gaspar Nicolas encontrámos vários tipos de incógnitas, a saber, a nova lei $L$, quando se fundem duas peças, se junta um metal precioso (prata ou ouro) ou cobre a uma dada peça. Mas também, pode ser desconhecido o peso do metal a juntar para se conseguir uma lei de metal precioso estabelecida à partida. Passemos a ilustrar com alguns exemplos contemplados pelo autor.

"Se te dixesem bulhão tenho de duas sortes huũ he de ley de .7. dinheiros e o outro de ley de.9. dinheiros e destas duas sortes quero fazer hũa liga que seja de ley de.11. dinheiros e quero fazer .50. marcos e quero tomar tres tanto de ley de .7. ora eu demando quãto tomarey de cada hũa sorte e quanta prata fyna lhe ey de lançar." (NICOLAS, 1963, f. xf)

A resolução dada é muito extensa mas dá-nos informações necessárias para uma melhor compreensão do enunciado. $\mathrm{O}$ autor propõe misturar duas ligas de prata e cobre com prata fina, ou seja, três tipos diferentes de misturas ${ }^{9}$. Se usarmos a nomenclatura anterior e face ao exposto, temos os dados seguintes

$$
\left\{\begin{array}{c}
L_{1}=7 \\
L_{2}=9 \\
L_{3}=12 \\
L=11 \\
P_{1}+P_{2}+P_{3}=50 \\
P_{1}=3 P_{2}
\end{array}\right.
$$

Pretende-se determinar os valores de $\boldsymbol{P}_{\mathbf{1}}, \boldsymbol{P}_{2}, \boldsymbol{P}_{3}$. Este enunciado, leva-nos a pensar no seguinte sistema

Onde para o problema proposto

$$
\left\{\begin{array}{c}
P_{1}+P_{2}+P_{3}=P \\
P_{1} L_{1}+P_{2} L_{2}+P_{3} L_{3}=L P \\
P_{1}=3 P_{2}
\end{array}\right.
$$

$$
\left\{\begin{array}{c}
P_{1}+P_{2}+P_{3}=50 \\
P_{1} L_{1}+P_{2} L_{2}+P_{3} L_{3}=550 \\
P_{1}=3 P_{2}
\end{array}\right.
$$

${ }^{9}$ A palavra bulhão é usada como designação para a liga de prata e cobre. 
A resolução do sistema conduz-nos aos resultados do autor. E o processo descrito é muito minucioso como podemos ler nas suaa próprias palavras:

“...se ho saber quiseres tem esta regra geral vee ho cobre que tem cada huũ onde aquelle bulham de .7. tera .5. dinheyros de cobre e ho de nove terá tres de cobre. E por que diz que quer.3. tanto do de.7. e tu sabes que ho de.7. tem .5. dinheiros de cobre multyplica tres vezes .5. e faras 15. ajuntalhe hos .3. que tem o bulham de.9. e sam.18. Ora este he ho teu partidor e por que diz que quer.50. marcos de ley de.11. e tu bem ves que pera .12. faltam huĩ onde mostra que cada marco há de ter huũ dinheiro de cobre e .50. marcos ham de teer .50. dynheiros de cobre. Ora parte estes .50. por.18. vem .2. e sete noveavos e tanto ha de tomar do bulham que he de ley de .9. e por que diz que quer tomar tres tanto do bulham de ley de .7. multiplica estes .2. e sete noveavos por .3. e faras.8. e huũ terço e tãto has de tomar daquele bulham de ley de.7. e pera saberes quantos marcos de prata fyna lhe as de lançar assoma .8. e huũ terço em .2. e sete noveavos e sã por todos onze e huũ novavo estes tyra .50. marcos que dyzes que queres fazer e fycam .38. e oyto novavos $e$ tantos the as de lançar de prata fina." (NICOLAS, 1963, f. xf)

Os problemas das ligas podem-nos conduzir a sistemas indeterminados, dando-nos o autor a solução conveniente. Um dos casos referidos é o seguinte:

"Bulham tenho de .3. sortes .s. huũa sorte de.10. dinheiros e outra sorte de.8. dinheiros e outra sorte de .6. dinheiros e destas .3. sortes queria fazer huũa liga que tivesse por marco .9. dinheiros e queria fazer .60. marcos. Ora eu demãdo quantos marcos tomarey de cada huũ.' (NICOLAS, 1963, f. xiif)

A diferença entre este enunciado e os anteriores é que falta uma condição que relacione dois dos valores dos «pesos». Podemos pensar que as incógnitas são $P_{1}, P_{2}, P_{3}$ e temos

No problema em causa

$$
\left\{\begin{array}{c}
P_{1}+P_{2}+P_{3}=P \\
P_{1} L_{1}+P_{2} L_{2}+P_{3} L_{3}=L P
\end{array}\right.
$$

$$
\left\{\begin{array}{c}
P_{1}+P_{2}+P_{3}=60 \\
10 P_{1}+8 P_{2}+6 P_{3}=540
\end{array}\right.
$$

Como já referimos, sendo o sistema indeterminado, uma das soluções é a que o autor nos apresenta $P_{1}=40, P_{2}=10$ e $P_{3}=10$. A sua resolução é a que passamos a descrever:

A resolução exposta em (Nicolas, 1963, f. xii ) é muito extensa e invoca a regra de três para encontrar as incógnitas. Queremos referir esta dupla designação «ley» e «fineza», 
presentes no enunciado e que parecem ambas referir-se à proporção de metal precioso presente na liga. No caso da prata temos $0 \leq L \leq 12$, onde $L=0$ corresponde à lei para um metal de baixo valor, como o é o cobre e $L=12$ corresponde à prata pura.

No tratado observamos enunciados que nos remetem para problemas que vão do mais simples ao mais complexo, como o é a situação que acabamos de descrever. Do ponto de vista matemático, estes problemas, no seu aspeto mais complexo, conduzem-nos a sistemas lineares indeterminados. As variáveis em jogo encontram-se ligadas à ideia de «medir» quantidades com o objetivo de ter uma maior ou menor lei do metal precioso numa dada liga metálica.

\section{As regras específicas do comércio português Quarto e vintena e conta de Flandres}

Como referiu (Clain, 2016), os tratados de aritmética, escritos um pouco por toda a Europa, caracterizam-se por um tronco comum constituído por um conjunto de regras como as companhias e as baratas. Contudo, as regras comerciais, poderão apresentar algumas características locais e, no caso da Pratica de Nicolas, consideramos que a presença da regra de quarto e vintena e da regra da conta de Flandres é um contributo «local» e uma via de modelização aritmética utilizada pelos mercadores de Quinhentos. Não se conhecem outros tratados que as contenham, para além dos tratados portugueses.

As regras de companhias, as baratas, as ligas e os câmbios, diretamente ligadas ao mundo mercantil, como afirmam os próprios autores, são partilhadas por um conjunto de tratados escritos nos séculos XV e XVI, onde se enquadram as obras escritas na Península Ibérica. A conceção destas obras tem por base um conjunto de modelos que serviam mercados e mercadores, no seu quotidiano. Queremos ainda referir a presença de uma forte componente formativa, imprescindível aos que se queriam movimentar numa teia comercial com características bastante complexas de diversos pontos de vista: distribuição de lucros, valorização/desvalorização de produtos, câmbios, fabrico de metais preciosos, variações de valores, impostos, entre outros. As aritméticas portuguesas, à semelhança das obras escritas noutros países para o mesmo fim, apresentaram modelos aritméticos e acompanharam esta tendência para responder às necessidades através da formação dos mercadores como o referem os seus autores. A perceção da necessidade de modelos eficazes no quotidiano dos negócios levou Gaspar Nicolas a escrever sobre dois temas «locais» e relativos aos negócios nacionais com projeção internacional, como o foi o comércio das especiarias. A regra de quarto e vintena propõe um modelo para o cálculo de um imposto na Casa da Índia sobre as mercadorias do Oriente. A regra da conta de Flandres aparece como um modelo aplicado à «viagem das mercadorias» pela Europa através da feitoria da Flandres. Viajar implicava variações de «preços», «pesos» e «medidas». O próprio capital vai até às praças mais famosas numa procura de aplicações financeiras com vista a um melhor rendimento. Nicolas é um ator neste palco de forte interação entre o mundo real e o modelo aritmético As suas palavras traduzem uma forte compreensão do papel dos modelos aritméticos para uma representação da realidade comercial. 


\subsection{Matemática «pour elle même»-uma emancipação do saber matemático relativamente ao real \\ As «Caminhadas»}

No fólio 36 da Pratica d'Arismetica podemos ler o título seguinte: «Aqui começam as progressões» (Nicolas, 1963, f. 36 v). «Definição» não existe e Nicolas começa por familiarizar o leitor com exemplos ${ }^{10}$. O objetivo é claro: determinar as somas dos termos. Por exemplo, somar os termos 2, 4, 8, 16, 32, 64 e 128 de uma progressão geométrica de razão 2. Observando a organização proposta, no nosso entender, o autor quis dar as bases para a resolução dos problemas de «Caminhadas».

O modelo de enunciados referidos aparecem a partir do fólio 42 , e são resolvidos recorrendo à regra da soma de $n$ termos consecutivos de uma progressão. Aqueles problemas inserem-se no tema «Números»e abordam subtemas diversos. Temos, por exemplo, dois homens que caminham, sendo usadas as progressões aritméticas 9, 18, 27, $36, \ldots$ e $1,2,3,4, \ldots$ dado que um dos homens anda cada dia 9 léguas e o outro, cresce cada dia 1 légua. Pretende-se saber quando se encontram pela primeira vez. A solução dada consiste em dobrar 9 e tirar 1, tendo-se 17 (Nicolas, 1963, f. 53 f). Em linguagem atual, podemos resolver a equação do segundo grau $9 n=\frac{n(n+1)}{2}$. Para «fugir» à da equação de grau dois, Nicolas ${ }^{11}$ pensa na expressão equivalente $9=\frac{n+1}{2}$, onde $n=9 \times 2-1=17$.

Encontramos problemas idênticos com algumas variantes quanto às questões e tipo de progressão a utilizar. Vejamos alguns exemplos.

"Dous vam a caminhando desta maneira que o primeyro no primeyro dia anda .21. leguoas e no outro dia outro tanto e assy sempre cada dia anda 21. leguoa. E outro vay caminhando nesta maneyra per numero desparo .s. ho primeyro dia anda huũa leguoa e o segundo dia anda tres e o terceyro dia anda .5..E assy vay procedendo atee que ho alcança. Ora eu demando em quantos dias sera com elle e quantas leguoas tera cada huũ." (NICOLAS, 1963, f. 53f)

Nos dois problemas descritos há uma vontade de praticar o método utilizado. Contudo, repare-se que nos dois enunciados o primeiro homem anda o mesmo número de léguas em cada dia enquanto o segundo vai variando em sequências de números que, neste caso são ímpares.

\footnotetext{
${ }^{10}$ Nestes exemplos encontrámos progressões aritméticas ou geométricas.

${ }^{11}$ Nicolas apresenta outros problemas de «Caminhadas» e, no último desses problemas, refere que tirou este assunto da obra de Frei Lucas, frade de S. Francisco, acrescentando que «...tirey muytas destas questões que o meu engenho nom abastaria ha fazer obra sem primeyro ho nom veer muyto bem.» (NICOLAS, 1963, f. 54v)
} 
Observamos outras propostas do autor no sentido de repetir o processo de resolução. Assim, temos, um conjunto de problemas onde pode acontecer o seguinte (Nicolas, 1963, ff. $53,54 f)$ :

- um homem anda cada dia 30 léguas e o outro anda 2 léguas no primeiro dia, 4 no segundo, no terceiro dia 6 e assim sucessivamente (sucessão de números pares);

- o primeiro homem anda cada dia 60 léguas e o segundo homem anda 3 léguas no primeiro dia, 6 no segundo e assim por adiante (sucessão de múltiplos de 3);

- o primeiro homem anda cada dia 60 léguas e o segundo homem anda 5 léguas no primeiro dia, 10 no segundo, 15 no terceiro dia e assim por adiante (sucessão de múltiplos de 5);

- um homem anda cada dia 12 léguas e o outro anda 4 léguas no primeiro dia, 8 no segundo, e assim aumentando cada dia 4 léguas (sucessão de múltiplos de 4);

Segundo Nicolas, todos os problemas se resolvem de modo semelhante. No final deste conjunto de enunciados, em jeito de nota, afirma o seguinte:

"Porem see avisado que quando ho numero que ho primeyro (homem) ho qual as de partir por ho que o segundo (homem) vay cresçêdo que quando o repartires e na repartiçam vier quebrado ha tal regra nam se podera fazer por esta via mays antes por outra como logo veras segundo Frey Lucas frade de Sam Francisco que foi nesta arte grande mestre que compilou e compos huũa obra darismetica e geometria .s. declarou .11. livros de geometria e.4. darismetica de Euclydes e he de muyta authoridade e chamase ho somario desta obra do frade. Eu delle tyrey muitas destas questões que ho meu engenho nom abastaria ha fazer obra sem primeyro ho nom veer muyto bem." (NICOLAS, 1963, f. 54v)

Com esta afirmação podemos admitir que a obra de Pacioli é uma fonte declarada para Gaspar Nicolas. Para explicar a exceção à regra anteriormente descrita, o autor descreve e resolve um problema de caminhadas. O enunciado é semelhante aos anteriores: Dois homens fazem uma caminhada na qual o primeiro anda cada dia 10 léguas e o segundo anda no primeiro dia 3, segundo dia 6, no terceiro dia 9 e assim sucessivamente, até termos a progressão $3,6,9,12, \ldots$. Temos duas questões: «Em quantos dias se encontram?» e «Quantas léguas terá andado cada um deles?» (Nicolas, 1963, f.54 v). Mais uma vez um leitor é alertado que a regra não é a utilizada nos problemas anteriores. Façamos um resumo das suas afirmações: ao partir 10 por 3 vem $3 \frac{1}{3}$ que dobrado faz $6 \frac{2}{3}$ Subtraímos 1 e fica $5 \frac{2}{3}$ e em tantos dias serão os dois homens juntos mas «nom pontualmente como atras he dyto» (Nicolas, 1963, f.54 v). A natureza do número encontrado como solução «compromete» a regra que funcionou sempre nos casos anteriores! O autor prossegue afirmando «Mas nos queremos achar a verdade...» (Nicolas, 1963, f.55 f). A verdade declarada consiste em ver quantas léguas andou cada homem em 5 dias, sendo posto de parte o valor fracionário. Assim, temos 50 léguas para o primeiro homem e 45 para o segundo. Como se poderiam os homens ter-se encontrado? Está claro 
para o autor que será necessário uma parte de um dia para estabelecer a «igualdade». Deste modo atribui mais uma jornada a cada homem e, em parte desse sexto dia dar-se-á a igualdade. Neste dia o primeiro homem faz 10 léguas e o segundo 18, ou seja, mais 8 léguas. Pela regra de três tem-se «.8. léguas sobejam de huũa jornada que parte da jornada me sobejam .5. leguoas...» (Nicolas, 1963, f.55 f). E, vem a resposta, $\frac{5}{8}$ da jornada. Os passos seguintes são dedicados a confirmar de que tudo bate certo para um total de $56 \frac{1}{4}$ léguas, o que podemos traduzir pelas expressões: $10 \times \frac{5}{8}=6 \frac{1}{4}$ e $18 \times \frac{5}{8}=11 \frac{1}{4}$ e $50+6 \frac{1}{4}=56 \frac{1}{4}$ e $45+11 \frac{1}{4}=56 \frac{1}{4}$.

\section{Os «Números»}

«Numeros» (Nicolas, 1963, ff.39-56) é o título dado por Gaspar Nicolas a uma parte do tratado onde aparece um conjunto de enunciados que, embora considerados clássicos e desligados do mundo mercantil, demonstram uma vontade em conhecer e transmitir conteúdos emancipados do real e associados a um esboço da «teoria dos números».

Muitos dos problemas relacionados com números e com falsas situações comerciais são resolvidos pelas regras de falsa posição ou oposições, como as designa Gaspar Nicolas. Sobre as oposições diz-nos o autor «Se quiseres saber ho modo das oposições teras em tua memoria que menos e menos se tira huũ do outro. E mais e mais se tira huũ do outro e mais e menos sempre se ajũta...» (Nicolas, 1963, f. 27 v). Esta afirmação é explicada com mais detalhe à frente: «...se he mais por huũa parte e mays pella outra que daquello que he sobejo que tires huũa da outra e ho que te ficar sera teu partidor e na partiçam sera multiplicando ambas has cruzese depois que forem multiplicadas tiraras huũa da outra e ho que te ficar sera tua partiçam.» (Nicolas, 1963, f. 28 f). No discurso está em causa a aplicação da regra de dupla falsa posição. Se usarmos a linguagem atual, podemos dizer que se aplica a equações do tipo $a x+b=c_{y}(a \neq 0)$ (1). A solução da equação é encontrada através do uso de dois números falsos. Se $x_{0}$ é o primeiro número falso, temos $a x_{0}+b=c_{0}(2)$. Se $x_{1}$ é o segundo número falso então $a x_{1}+b=c_{1}$ (3). Subtraindo membro a membro as duas expressões (1) e (2), temos $a\left(x-x_{0}\right)=c-c_{0}$. Subtraindo também, membro a membro, as expressões (1) e (3), temos $a\left(x-x_{1}\right)=c-c_{1}$. Fazendo $d_{0}=c-c_{0}, d_{1}=c-c_{1}$ e dividindo as igualdades $a\left(x-x_{0}\right)=d_{0}$ e $a\left(x-x_{1}\right)=d_{1}$ membro a membro e resolvendo em ordem a $x$ temos

$$
x=\frac{d_{0} x_{1}-d_{1} x_{0}}{d_{0}-d_{1}}
$$

As precauções do autor encontram-se ligadas aos valores das diferenças no numerador e no denominador, daí mencionar, com detalhe, todas as possibilidades. Para 
consolidar a regra descrita existe, no tratado, um conjunto de problemas com temas comerciais ou sobre a teoria dos números. Entre os primeiros temos, por exemplo,

“...huũ homẽ partiu de Lisboa pera Santarem e nom sabemos quanto dinheiro levava (...) em Sacavem dobrou o dinheiro que levava he gastou .20. reaes e ficou the ainda dinheiro e foy se a Vila Franca e dobro o dinheiro que the ficou e gastou 20 . reaes e ficou the ainda dinheiro e chegou a Santarem e dobrou este dinheiro que lhe ficou e gastou .20. reaes e nom the ficou nada.»" (NICOLAS, 1963, f. 28 f).

Há duas ações que se repetem: dobrar e gastar 20 reais. Se traduzirmos o enunciado em linguagem atual, depois de seguirmos os passos descritos, temos a resolver a equação $8 x-140=0$, cuja solução é 17,5 . Gaspar Nicolas usa dois números falsos, 17 e 18, e vai, com cada um, repetindo as ações descritas. Ou seja, quando considera o 17 tem como resultados intermédios: $17,34-20=14,28-20=8,16$ e faltam 4 para 20 , logo fica sem efeito a ação em Santarém. Para o 18 temos: $18,36-20=16,32-20=12,24-20=4$ que não é o zero pretendido. Em (3) temos $d_{0}=4$ e $d_{1}=-4$ («... .4. que mingoaram...» (Nicolas, 1963, f. 28 f), ou seja, -4) e vem a solução

$$
x=\frac{4 \times 18+4 \times 17}{4+4}=17 \frac{1}{2}
$$

O tratado contém outros problemas com as mesmas características, estando em causa a duplicação de certas quantias e o gasto que se mantem constante em cada cidade por onde passa o tal homem. Todos são resolvidos por dupla falsa posição. Contudo, no caso em que a quantidade a gastar é um múltiplo de 2 e mantendo-se a duplicação, Nicolas afirma: «...podes fazer esta conta sem oposição...» (Nicolas, 1963, f. 28 v). Para o efeito, no caso do problema anterior, considera sucessivas «metades». Como são gastos 20 reais em cada um dos três locais, depois de duplicar a quantia conseguida na cidade anterior, as metades são 10,5 e $2 \frac{1}{2}$ que somadas dão a solução pretendida. Repare-se que na equação $8 x-140=0$ é equivalente a $8\left(x-\frac{35}{2}\right)=0$, onde $8=2^{3} \quad$ e $\frac{35}{2}=\frac{20}{2}+\frac{10}{2}+\frac{5}{2}=10+5+\frac{5}{2}$, a referida soma das três «metades».

No sentido de trabalhar algumas propriedades dos números, a «oposição» serve para resolver um conjunto alargado de problemas sob temas diversos e que, como já afirmamos, são considerados clássicos nestas obras. Temos por exemplo «...três homens que queriam mercar um cavalo que valia .60. cruzados...» (Nicolas, 1963, f. 31 v). As condições assumidas envolvem as frações $\frac{1}{2}, \frac{1}{3^{\prime}}$ e $\frac{1}{4}$, cujos denominadores são três números naturais consecutivos, seguindo as condições: 


\section{Teresa Costa Clain}

O primeiro homem disse ao segundo: «...se me das o meyo do teu com o que eu tenho eu mercarey este cavallo...» (Nicolas, 1963, f. $31 \mathrm{v}$ );

O segundo homem disse ao terceiro: «...se me das o terço do teu com o que eu tenho eu mercarey este cavallo...» (Nicolas, 1963, f. $31 \mathrm{v}$ );

O terceiro homem disse ao primeiro: «...mas dayme vos amy o quarto do que vos tendes e com ho que eu tenho eu mercarey o cavallo...» (Nicolas, 1963, f. $31 \mathrm{v}$ ).

Em linguagem atual podemos traduzir este discurso, designando por $x_{z}, y_{z} z$ as respetivas quantias do primeiro, segundo e terceiro homens, pelas condições

$$
\left\{\begin{array}{l}
x+\frac{1}{2} y=60 \\
y+\frac{1}{3} z=60 \\
z+\frac{1}{4} x=60
\end{array}\right.
$$

Não é a primeira vez que laivos de uma Matemática sem aplicações diretas na vida dos mercadores aparece, o que demonstra uma vocação do tratado mais distante do ambiente mercantil.

$\mathrm{Na}$ maioria dos problemas estão envolvidos processos lineares onde a regra de três marca a sua posição. Aparece associada a procedimentos de falsa posição ${ }^{12}$. Nicolas menciona situações de impossibilidade, e mesmo aqui, a regra de três é um meio de

12 Podemos recordar que a falsa posição (simples) é muito antiga e aplica-se a problemas que atualmente traduzimos por equações do tipo $a x=b_{s}(a \neq 0)$. A regra de três, aplicada à falsa posição, pode ilustrar-se, de modo geométrico, pela semelhança de triângulos.

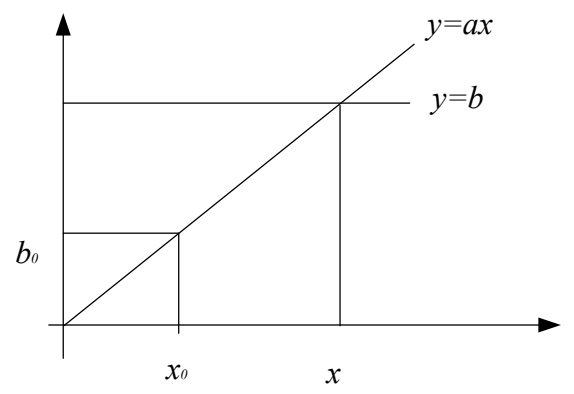

Observando a figura podemos deduzir a relação $\frac{x}{x_{0}}=\frac{b}{b_{0}}$. Na figura, $x_{0}$ é o número falso e $b_{0}$ o resultado que advem de considerar um «número falso qualquer». Todos os problemas enunciados se reduzem a uma equação do tipo $a x=b_{s}(a \neq 0)$. Os problemas que conduzem a equações do primeiro grau são numerosos na literatura matemática, em particular nos tratados de aritmética prática, tendo sido Leonardo de Pisa um dos responsáveis pela sua divulgação. Este tipo de problemas foi passando de obra em obra através dos tempos e, os tratados portugueses não fugiram a esta tradição. 
justificação. Por exemplo no enunciado, «Buscame hũ numero que lhe tirando dous terços e o meo fiquem .10. » (Nicolas, 1963, f. 42 v). Para justificar que a «conta é falsa» o autor afirma: «...tu bem ves que ho meo e dous terços que passa de cousa enteira e não podes tirar este meo e dous terços de nenhuũ numero que fique alguũa cousa minguar» (Nicolas, 1963, f. 42 v). Para reforçar as suas afirmações, usa o número 6, assim determina um meio e dois terços de 6 que somados fazem 7. O «minguar», neste caso, quer dizer que $6-7=-1$. A partir deste exemplo são enunciados outros cuja resposta vem pela regra de três. Por exemplo, «se de .6. minguaram huũ de quantos me minguaram .20. » (Nicolas, 1963 , f. 42 v). Usando, implicitamente a regra de três, o autor conclui que a resposta é 120 , ou seja, se somarmos um meio e dois terços de 120 , temos 140 e $120-140=-20$ («minguar te am .20.» (Nicolas, 1963, f. 42 v)). À impossibilidade denunciada à partida o autor «dá a volta» aplicando a proporção e, desta maneira, o «minguar» é admitido.

Os enunciados de problemas com números do fólio $42 \mathrm{v}$ incluem números e raízes, tais como este: «Dame huũ numero que partido o seu terço por sua rayz venham .19. » (Nicolas, 1963, f. 42 v). Podemos-lhe associar uma a equação

$$
\frac{1}{3} x=19 \sqrt{x}
$$

O autor vai agir, de modo retórico, no sentido de transformar a expressão noutras tais como $x=57 \sqrt{x}$ e por elevação de ambos os membros ao quadrado vem $x^{2}=3249 x$. As duas soluções são 0 e 3249, sendo esta última a única solução considerada.

No universo dos problemas apresentados podem incluir-se alguns problemas sobre números quadrados:

"Da me huũ numero que lhe poendo .10. fique quadrado e tirãdo .10. fique quadrado. Este he o modo por que diz .10. multiplica.10. em sy e fazem .100. ajũta sempre .4. por regra geral e fazem .104. ora sempre parte por .4. por regra geral vem .26. (...)" (NICOLAS, 1963, f. 43 f).

A «regra geral referida» não se encontra enunciada anteriormente e a resposta apresentada não carece de qualquer justificação por parte do autor. Se passarmos à linguagem atual podemos ter as equações do problema

$$
\left\{\begin{array}{l}
x+10=a^{2} \\
x-10=b^{2}
\end{array}\right.
$$

Onde $x$ representa o número a determinar, $a^{2}$ e $b^{2}$ são os números quadrados referidos. Se fizermos $(1)+(2)$ temos $2 x=a^{2}+b^{2}$ e fazendo (1) - (2) temos $20=a^{2}-b^{2}$. Sabendo que $a^{2}-b^{2}=(a+b)(a-b)$, procuram-se dois divisores de 20. A solução dada considera

$$
\begin{aligned}
& a+b=10 \text { e } a-b=2 \text {. Daqui resulta que } a=6 \text { e } b=4 \text {. Ou seja, } \\
& 2 x=6^{2}+4^{2} \Leftrightarrow x=26 .
\end{aligned}
$$

Na regra geral referida por Nicolas temos 
$(a+b)^{2}+(a-b)^{2}=10^{2}+2^{2}=2\left(a^{2}+b^{2}\right)=2(2 x)$ então $4 x=104 \Leftrightarrow x=26$.

\section{«Preguntas»}

Sob a designação de Preguntas (Nicolas, 1963, ff. 47-77) Gaspar Nicolas exibe outros problemas. Trata-se, não só, de um conjunto de enunciados para consolidação das regras mas também um meio de abordar outros temas. Observa-se uma mistura entre situações que reportam aspetos dos números e outras de caráter mais lúdico, ou sobre regras comerciais. Para além dos já citados anteriormente, temos outras variantes como mercar uma casa ou outra coisa indefinida, no sentido da prática do algoritmo. A venda de ovos, partir um peixe, cavar um poço, construir um sino, testamentos e heranças, prisioneiros em terra de mouros, bolsas com dinheiro, viagens, entre outros, são alguns dos temas de uma miscelânea de enunciados que visam também o entretenimento.

\section{Geometria}

O Tratado da Pratica d'Arismetica é, entre os tratados escritos para o mesmo fim na época, aquele que aborda a «Geometria» (Nicolas, 1963, ff. 81-94). Nos tratados ibéricos de aritmética prática escritos nos séculos XV e XVI não é muito comum a presença de uma secção de Geometria. Os que antecederam a primeira edição da obra de Nicolas, o Summa de l'art d'aritmética (1482) de Francesc Santcliment e o Sumario breve de la pratica de la Arithmetica (1515) de Juan Andrés não abordam o tema. É Juan Ortega que o faz em 1512 no seu tratado de aritmética (Ortega, 1512, pp. 193-205) e escolhe apresenta-lo no capítulo final do tratado. Esta foi também a escolha de Gaspar Nicolas, considerando que as regras da liga da prata são um apêndice que merece uma paginação diferente. De que Geometria se trata? É uma geometria da «medida» aplicada a triângulos, quadrados, círculos, fortalezas e torres. O desenvolvimento dos assuntos assenta em exemplos trabalhados com ou sem unidades de medida. Observamos enunciados que ainda hoje encontramos nos manuais escolares, tais como o seguinte:

"Sam duas torres huũa de .90. braças e outra de .80. e esta arredada huũa da outra .100. braças. E entre ambas as torres esta huũa fonte em tal lugar que duas aves yguaes no voar vem beber aquella fonte .s. que cada uma das torres tem duas aves em çima e partem ambas ha huũ tempo e chegam ambas ha huũ tempo ha fonte. Demando quanto esta ha fonte arredada de cada torre..." (NICOLAS, 1963, f. 91) 


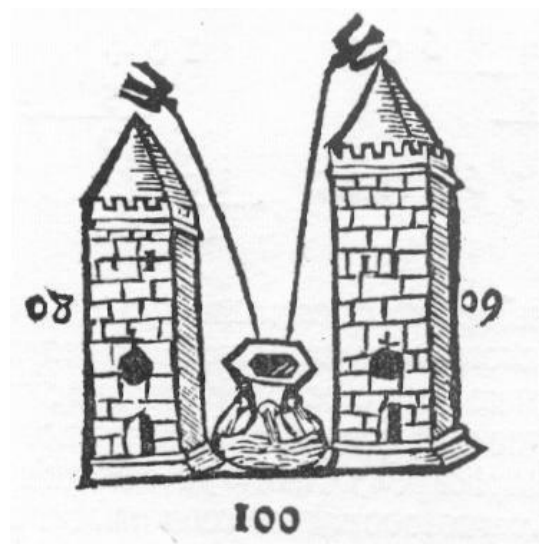

Fig. 5 O problema da fonte (Nicolas, 1963, f. 91)

O Tratado da Pratica d'Arismetica diferencia-se dos outros tratados portugueses por incluir as temáticas em geometria que referimos, e ainda outros problemas, neste tema, com características mais lúdicas, como os problemas das duas torres, da árvore que quebrou, do chafariz, entre outros que fazem parte de um passado herdado ao longo de gerações de sábios, sendo em muitos casos difícil determinar a sua proveniência.

\section{As fontes \\ Luca Pacioli}

Que obras matemáticas teriam inspirado Gaspar Nicolas a compor o seu tratado? De um modo geral esta é uma questão sem resposta para muitos tratados semelhantes. Habitualmente as fontes são omissas, a noção de plagiato não existia e os autores, como viria a referir Guiral Pacheco «comiam todos por mão alheia» (Pacheco, 1624, prologo). Contudo, no Tratado da Pratica d'Arismetica podemos encontrar algumas citações à obra de Luca Pacioli: «Frey Lucas de Sam Francisco que foi nesta arte grande mestre que compilou e compôs huũa obra d'arismetica e geometria» (Nicolas, 1963, f. 51 f). Sendo aquele autor citado, podemos considerar a sua obra uma «fonte segura». Alguns estudos confirmam que o Summa de Arithmetica Geometria Proportioni et proportionalita de Luca Pacioli, editado em 1494, parece ter sido uma fonte e um modelo de organização que predominou na arquitetura dos tratados ibéricos, tal como o sublinha Javier Docampo Rey em (Docampo, 2006). A referência a Pacioli e a Bradwardine é dada pelo próprio Gaspar Nicolas ao abordar o problema das laranjas (Nicolas, 1963, f. 72 f). A par com Bradwardine vem o nome de Euclides e, segundo Nicolas, duas fontes de Pacioli.

"Huũ homem espalhou .100. laranjas e dyz ha outro que as apanha huĩa a huĩa todas em huũa pinha. Ora eu demando em quantos passos apanhara aquella pinha aquellas laranjas tu saberás que ho frade poem 
esta questam per estes mesmos termos e diz que has laranjas seram apanhadas em .10100. passos e por que hos passos de .100. laranjas nam sam tantos querem dizer alguũs que escreveu falso. E que ho nam sentio e eu diguo que nã que nã he de creer que quẽ tyrou tã sotys regras como elle que entendia todas as obras de Euclydes assy de gyometrya como de arismetyca e reprendeo a Bernardyno na gyometrya como podes veer na sua obra. Nam posso creer que obra escrepvesse falsa salvo nam entendem as regras hos que taes reprensoões fazem por que dyzem que .100. laranjas sam apanhadas em .9900. passos verdade he que assy seria se começasse apanhar da primeyra laranja mas ha vello d'entender que estee .100. passos d'espaço conven asaber que quando elle começar a apanhar que se hada faltar huũ passo pera as apanhar todas .100." (NICOLAS, 1963, f. 72 f).

O enunciado carece de alguma informação. Não sabemos como se dispõem as laranjas face a quem as vai apanhar. Assim, podemos ter em conta que as laranjas seguem uma distribuição separadas por passos da mesma dimensão e podemos ter duas situações: -o homem que apanha está afastado de qualquer laranja e teremos a solução de Pacioli, 10100 passos. Basta considerar o somatório $\sum_{i=1}^{100} 2 \mathrm{i}=10100$.

-o homem está junto a uma laranja e assim não terá necessidade de dar qualquer passo para a apanhar, temos o somatório $\sum_{i=0}^{99} 2 \mathrm{i}=9900$.

Como podemos observar não é dado o nome do frade mas depreende-se ser Luca Pacioli. A situação relatada remete-nos para a análise de um resultado. Gaspar Nicolas não só se manifesta de acordo com a solução do frade como critica aqueles que põem em causa o seu saber. São exaltados os grandes conhecimentos de Pacioli em detrimento dos seus críticos que, segundo Nicolas, não entenderam as regras. Contudo, todos têm razão!

\section{Juan Ortega}

Almeida (Almeida, 1994, v. I, p. 100) refere que Juan Ortega exerceu clara influência nos aritméticos do seu tempo. O mesmo é reforçado por Rey Pastor quando afirma,

"La Aritmética de Ortega alcanzó merecida fama en toda Europa, como lo prueban los elogios a de sus contemporâneos y las numerosas ediciones que alcanzó. Esta favorable estimación se refiere al carácter práctico del livro, escrito como dice su autor, "porque no passassen tantos fraudes como passan por el mundo acerca de las cuentas.»" (REY PASTOR, 1934, p. 71).

A popularidade do trabalho de Ortega é ainda reconhecida por M. Labarthe,

“... Publicado sob o título Tratado subtilíssimo de Arismetica y de geometria (titulo dado em particular à edição de Sevilha de 1534). Foi, 
se tivermos em conta o número de edições imprimidas, a mais popular das aritméticas da época. É também, de longe, a mais volumosa ${ }^{13}$ ".

Podemos admitir que a popularidade de Ortega chegasse a Portugal e colocar a hipótese de que tenha sido uma fonte para Gaspar Nicolas, embora este nunca o tenha mencionado. Na época a que nos reportamos os mundos lusitanos e hispânicos encontravam-se unidos por laços estreitos de partilha de negócios, saberes e objetivos em termos da expansão marítima. Esta vontade deliberada veio motivar trocas ao nível do saber e da cultura, em particular uma circulação de livros entre as duas regiões, o que será de esperar que também fossem sentidas ao nível da aritmética prática.

\section{Conclusão}

Os temas incluídos no Tratado da Pratica d'Arismetica fazem parte de uma tradição em aritmética prática, como as regras de companhias, as baratas, as ligas da prata e do ouro. Contudo, aquela obra é a primeira, no corpus aritmético português, a integrar duas regras comerciais «locais». Trata-se da regra de quarto e vintena e da regra da conta de Flandres. Estas duas regras têm a sua origem no comércio português com o Oriente e mostram bem a interação entre os saberes e a realidade envolvente através da presença de modelos aritméticos na vida económica.

O referido tratado marca uma certa modernidade dado que, o número perde a sua figura outrora especulativa e define-se enquanto entidade de medida, impondo o seu estatuto e, a aritmética é vista como uma «escada» para alcançar outros saberes.

O modo como Nicolas estrutura o seu tratado é de certo modo «desarrumado», dado que, por vezes há temáticas diferentes que partilham espaços contíguos. Contudo, no seu discurso há uma manifesta intensão de bem ensinar, baseando-se na prática repetida dos algoritmos propostos e nas chamadas de atenção ao aprendiz. Quem seria o público visado? Para além dos funcionários da Casa da Índia há que considerar um público pouco escolarizado mas com atividades ligadas ao comércio, o que o leva a conceber regras «utilitárias», como a regra de três, nas primeiras páginas da obra. Para o mercador era necessário aplicar a regra e para os menos instruídos, a regra deveria ser clara e simples. Os casos mais complexos cabia aos aritméticos resolvê-los, como por exemplo nos diz Gaspar Nicolas a propósito das dúvidas que lhe são colocadas na Casa da Índia.

Gaspar Nicolas alicerçou o seu tratado na matemática mercantil e, os modelos aritméticos eram uma garantia aplicada à resolução das situações mais críticas embora, em alguns casos, elas fossem essencialmente académicas. Estas situações não são de modo algum inéditas, quando comparamos alguns tratados de aritmética prática. Os processos algorítmicos podem estar enquadrados nas regras comerciais e os temas, apresentam-se, por vezes, mascarados com enunciados comerciais.

\footnotetext{
13 «...Publié sous le titre de Tratado subtilissimo de Arismetica e geometria (titre donné en particulier à l'édition de Séville de 1534). Il fut, si l'on se rapporte au nombre d'éditions qui ont été tirées, la plus populaire des arithmétiques de de l'époque. C'est aussi, de loin, la plus volumineuse» (LABARTHE, 2004, v. I, p. 46).
} 
Interessou-nos averiguar o interesse do autor por temas da Matemática fora do mundo mercantil e deparamo-nos com um conjunto alargado de problemas para determinar números. $\mathrm{O}$ gosto pelos números poder-nos-ia levar a pensar que Nicolas concebe o número como ente abstrato, contudo assistimos a uma ambivalência entre o número por si só e pelo que representa.

O Tratado da Pratica d'Arismetica diferencia-se dos outros tratados portugueses por incluir temas da geometria da medida. Inclui ainda um conjunto de enunciados com características lúdicas que fazem parte de um passado herdado ao longo de gerações de sábios, sendo em muitos casos difícil determinar a sua proveniência. Contudo, Gaspar Nicolas cita em certas passagens um autor de grande reconhecimento na aritmética-Luca Pacioli. Enaltece o seu saber considerando-o o grande mestre na aritmética, o que nos permitirá situar o Tratado da Pratica d'Arismetica numa linha de trabalhos motivados por uma fonte comum na tradição da aritmética italiana.

\section{Bibliografia}

ALMEIDA, António Augusto Marques. 1994. Aritmética como descrição do real (15191679). Imprensa Nacional, Casa da Moeda, 2 vols. Lisboa.

Anónimo (século XIV). Libro de arismética que es dicho alguarismos, libro que enseña ensayar qualquier moneda. Edição B. Caunedo del Potro e R. Cordoba de la Llave 2000, El arte del alguarismo. Un libro castellano de aritmética comercial y de ensayo de moneda del siglo XIV. Junta de Castilla y Léon.

CLAIN, Teresa Costa. 2016. Les règles d'un quarte et un vingtième et des comptes de Flandre comme modélisation du réel. Em L. Radford, F. Firinghetti e T. Hausberg (eds.) Proceedings of the 2016 ICME Satellite Meeting, HPM 2016. 351-358, em Montpellier, julho 18-22, 2016.

DOCAMPO, Javier. 2006. Reading Luca Paciolis Summa in Catalonia: An early 16thcentury Catalan manuscript on algebra and arithmetic. Historia Mathematica, 33, pp 43-62. FERNANDES, Bento. 1555. Tratado da Arte de Arismetica. Francisco Correa, Porto.

FONSECA, José. 2010. Economia monetária e financeira. Imprensa da Universidade de Coimbra, Coimbra.

LABARTE,Marie-Hélène. 2004. Premières arithmétiques imprimées des Espagnes : une hiérarchie des problèmes au service des procédés de résolution. Dissertação de Doutoramento. Université Paul Sabatier. Toulouse III. Toulouse.

LEITÃO, Henrique. 2009. Os descobrimentos portugueses e a ciência europeia. Alêtheia Editores.Lisboa.

MACHADO, Diogo Barbosa. 1741-1759. Bibliotheca Lusitana historica, critica $e$ cronologica na qual se comprehende a noticia dos Authores Portuguezes, e das Obras, que compuserão desde o tempo da promulgação da Ley da Graça até o tempo prezente : Offerecida à Augusta Magestade de D. João V. Lisboa Occidental : António Isidoro da Fonseca (4 vols.). Lisboa.

MENDES, Ruy. 1540. Pratica darismetica nouamente agora composta pelo licenciado Ruy Mendez: na qual se descraram por boa ordem e craro estilo as quatorze especias darte darismetica .\&. as sete dellas por numeros inteyros e as outras sete por numeros 
quebrados: e assi mesmo trinta e cinco regras da dita arte muito sortil e breue $e$ craramente decraradas. Germão Galharde. Lisboa.

NICOLAS, Gaspar. 1963. Tratado da Pratica d'Arismetica. Edição fac-similada da edição de 1519. Livraria Civilização. Porto.

ORTEGA, Juan.1512. Tractado subtilissimo de arismetica y de geometria. Maistro Nicolau de Benedictis (por loannes Trinxer). Lyon.

PACHECO, Afonso Villafanhe Guiral. 1624. Flor da Arismetica Necessaria. Geraldo da Vinha. Lisboa.

PASTOR, Julio Rey. 1934. Los matemáticos españoles del siglo XVI. Junta de Investigaciones Histórico-Bibliográficas. Madrid.

TEIXEIRA, Francisco Gomes. 1934. História das Matemáticas em Portugal. Academia das Ciências de Lisboa. Lisboa.

\section{Teresa de Jesus Costa Pereira Caracol Clain \\ E-mail: tcostacaracol@gmail.com \\ CIDMA- Centro de Investigação e Desenvolvimento \\ em Matemática e Aplicações, \\ Departamento de Matemática - UA - Aveiro - Portugal}

This work was supported by Portuguese funds through the CIDMA - Center for Research and Development in Mathematics and Applications, and the Portuguese Foundation for Science and Technology ("FCT - Fundação para a Ciência e a Tecnologia"), within project UID/MAT/04106/2019. 